Received Date : 16-Sep-2015

Revised Date : 08-Jan-2016

Accepted Date : 10-Jan-2016

Article type : Clinical Investigation

\title{
An Examination of Racial and Ethnic Differences in End-of-Life Medicare Expenditures
}

Elena Byhoff, M.D. ${ }^{1,2,3,7}$, John A. Harris, M.D., M.Sc. ${ }^{3,4}$, Kenneth M. Langa, M.D., Ph.D. ${ }^{1,2,5,7}$, and Theodore J. Iwashyna, M.D., Ph.D. ${ }^{1,2,5,6}$

${ }^{1}$ Department of Medicine, University of Michigan, Ann Arbor, MI, USA; ${ }^{2}$ Veterans Affairs

Center for Clinical Management and Research, Ann Arbor, MI, USA; ${ }^{3}$ Robert Wood Johnson Foundation Clinical Scholars Program; ${ }^{4}$ Department of Obstetrics and Gynecology, University of Michigan, Ann Arbor, MI, USA; ${ }^{5}$ Institute for Social Research, University of Michigan, Ann Arbor, MI, USA; ${ }^{6}$ Australian and New Zealand Intensive Care Research Centre, Department of Epidemiology and Preventive Medicine, Monash University, Melbourne, VIC, Australia; ${ }^{7}$ Institute for Healthcare Policy and Innovation, University of Michigan, Ann Arbor, MI, USA.

\section{Corresponding Author:}

Elena Byhoff, Clinical Lecturer, Robert Wood Johnson Foundation Clinical Scholars Program, Veterans Affairs Center for Clinical Management \& Research, Department of Medicine, University of Michigan, 2800 Plymouth Road, Building \#10 Room G016, Ann Arbor, MI 481092800, phone (734) 647-4844, fax (734) 647-3301, email: byhoff@ med.umich.edu

\section{Alternate Corresponding Author:}

Theodore J. Iwashyna, email: tiwashyn@ med.umich.edu

Short title: Racial and Ethnic Differences in EOL Expenditures

This is the author manuscript accepted for publication and has undergone full peer review but has not been through the copyediting, typesetting, pagination and proofreading process, which may lead to differences between this version and the Version of Record. Please cite this article as doi: $\underline{10.1111 / \text { igs. } 14263}$

This article is protected by copyright. All rights reserved 


\section{ABSTRACT}

Objectives: To determine to what extent racial and ethnic variation in Medicare spending during the last six months of life are explained by demographic, social support, socioeconomic, geographic, medical and EOL planning factors.

Design: Retrospective cohort study

Setting: Health and Retirement Study (HRS)

Participants: 7,105 decedents who participated in the Health and Retirement Study between 1998-2012 and previously consented to survey linkage with Medicare claims.

Measurements: Total Medicare expenditures in the last 180 days of life by race and ethnicity, controlling for demographic factors, social supports, geography, illness burden, and EOL planning factors including presence of advance directives, discussion of EOL treatment preferences, and whether death had been expected.

Results: Our analysis included 5548 (78.1\%) non-Hispanic white, 1030 (14.5\%) non-Hispanic black, 331 (4.7\%) Hispanic, and 196 (2.8\%) adults of other race/ethnicity. Unadjusted results suggest that average Medicare expenditures for black decedents was $\$ 13,522(35 \%, p<0.001)$ more than for whites, while Medicare expenditures for Hispanics was $\$ 16,341(42 \%, \mathrm{p}<0.001)$ more at EOL. Controlling for demographic, socioeconomic, geographic, medical and EOL specific factors, the Medicare expenditure difference between groups reduced to $\$ 8,047$ (22\%, $\mathrm{p}<0.001)$ more for black and $\$ 6,855(19 \%, \mathrm{p}<0.001)$ more for Hispanic decedents compared to non-Hispanic whites' expenditures. The expenditure differences between groups remained statistically significant across all models.

Conclusion: Racial and ethnic differences in Medicare spending in the last six months of life are not fully explained by patient-level factors, including EOL planning factors. Future research should focus on broader systemic, organizational and provider level factors to explain these differences.

Keywords: end-of-life, disparities, Medicare, race and ethnicity

\section{INTRODUCTION}


An extensive body of evidence documents racial and ethnic differences in medical care at the end-of-life (EOL) (1-14). These include differences reported in intensity of care, reported patient preferences, and Medicare spending $(2,3,7,8,15)$. Black decedents have been found to spend between $28 \%$ and $37 \%$ more than white decedents $(5,7,14,16-19)$.

Despite examining individual and geographic factors that contribute to overall costs, there remains unexplained variation among racial and ethnic groups at EOL. Partial explanatory mechanisms include differences in preferences for more expensive, life-prolonging care among non-white minorities, with both quantitative and qualitative evidence for such differences $(5,16)$. However, established work suggests that these EOL preferences are not necessarily concordant with care received (3).

We sought to further understand elements that explain the association between race and EOL spending by examining a more complete array of patient level factors, including demographic, socioeconomic, geographic, medical and EOL planning variables. Guided by a modeling framework developed from prior research on mechanisms for racial health disparities (Figure 1) $(5,7,19,20)$, we used comprehensive data from the nationally representative Health and Retirement Study (HRS) to assess the extent to which racial and ethnic differences in EOL spending would be explained by these complex factors. By systematically examining multiple patient-level domains that have been associated with disparities in health care, we will better understand the causal pathways underlying the expenditure differences across racial and ethnic groups at the end of life. We hypothesized that the apparent racial and ethnic differences would be explained by these other factors not fully measured in past work.

\section{METHODS}

\section{Study Population}

We used data from the HRS, a biennial longitudinal survey of a nationally representative cohort of U.S. adults aged 51 or older that measures a broad range of scientific questions about health and aging (21). The HRS includes sufficient non-white minorities to examine racial and ethnic differences among older Americans. Telephone or in-person interviews with HRS participants are conducted every two years. During each interview cycle, HRS identifies 
participants who have died since the last core interview using information from family members and the National Death Index. Exit interviews are conducted with surviving family or friends who act as a proxy knowledgeable about the decedent.

We included HRS decedents aged 65 years or older who died between the 1998 and 2012 survey waves and who authorized that their HRS responses could be linked to Medicare claims data. We only included decedents who were continuously enrolled in Medicare Fee-For-Service parts $\mathrm{A}$ and $\mathrm{B}$ in the last six months of life in this analysis (22-24).

\section{Measures}

The primary outcome was total Medicare expenditures in the last six months of life. This measure includes all Medicare claims made for inpatient, outpatient, skilled nursing facility, durable medical equipment, home health care, physician supplier, and hospice care. All expenditures were adjusted for inflation (2012 U.S. dollars) using the medical component of the US Bureau of Labor Statistics Consumer Price Index. Our primary analytic interest was in the difference between white decedents and either black or Hispanic decedents in the primary outcome of interest.

We included demographic, social support, socioeconomic, geographic, and medical factors that have been shown in previous literature to be associated with Medicare expenditures in the last 6 months of life, as well as associated with differences in costs among racial and ethnic groups (Figure 1) $(5,7,14,19,20,25)$. Demographic and social support variables included self-reported race (non-Hispanic white, non-Hispanic black, Hispanic, other), age at death, gender, marital status (married, never married, divorced, widowed, other), residential situation (lives at home alone, lives at home with others, lives in nursing home) and birth cohort (grouped years of birth by predefined generations from the HRS codebook). We included birth cohort as an independent variable in addition to age to control for generational specific associations with healthcare knowledge and preferences.

Socioeconomic variables included educational attainment (<12 years, 12 years, 13-15 years, $\geq 16$ years), net worth by quartile, and non-Medicare insurance coverage (Medicaid, VA insurance, or Private insurance/Medigap). Geographic factors were included as urban residency determined by ZIP code, and using the End of Life Expenditure Index (EOL-EI) by quintile. Using the Dartmouth Atlas of Health Care, we linked each participant to a hospital referral region. The Dartmouth Atlas calculated End-of-Life Expenditure Index (EOL-EI), a measure of 
physician practice patterns based on utilization patterns among Medicare beneficiaries in the last six months of life for each hospital referral region. The EOL-EI takes into account regional variation and expenditure patterns that contribute to spending differences at $\operatorname{EOL}(26,27)$.

We included 30 Elixhauser comorbidities as individual factor variables for each decedent to control for illness burden contributing to expenditure differences in the last six months of life (28). Using the HRS cognitive functioning measures collected at the decedent's last survey interview, we included cognitive function variables. Cognitive function was categorized as normal, mild cognitive impairment, or dementia based on HRS validated definitions $(29,30)$. We also included functional status based on number of deficiencies in Activities of Daily Living (ADLs) collected during the last core interview. Functional status was categorized as no impairment (no ADL deficiencies), moderate impairment (1-3 ADL deficiencies) or severe impairment (4 or more ADL deficiencies).

End-of-life planning factors include presence of an advance directive, having discussed EOL treatment preferences prior to death, and having an "expected death." Proxy informants were asked in the exit interview "Was the death expected at about the time it occurred or was it unexpected?" If the informant answered yes, the death was considered an "expected" death.

\section{Data Analyses}

We used multivariable generalized linear regression to model the extent to which association between race/ethnicity and EOL spending could be accounted for by all known factors. Because of the positively skewed distribution of Medicare expenditure data, the models used a gamma distribution with a log link (31). Model coefficients generated by the regression models were exponentiated to transform the data into rate ratios (RR). We constructed five multivariable models with total Medicare expenditures as the outcome variable, adding sequentially the clusters of variables hypothesized to contribute to racial and ethnic differences in EOL Medicare expenditures. The clusters were added to the bivariate model (1) with race and ethnicity in the following order: (2) demographic and social support variables, (3) socioeconomic and geographic indicators, (4) illness burden variables, (5) EOL planning variables. We tested for differential effects of all independent variables on total Medicare expenditures by calculating the marginal effects by race or ethnicity.

We imputed covariates for which any data were missing using multiple imputation (5 cycles) (32). Missing data values were most frequent among presence of an advance directive 
(11\%), expecting death (9\%), discussed EOL treatment preferences (8\%), and having private or Medigap insurance (4\%). There were no significant differences in results of multivariable analyses using imputed or non-imputed variables. We performed all analyses using STATA 13 (StataCorp, College Station, Texas).

\section{RESULTS}

Our study sample included 7,105 Fee-for-Service Medicare beneficiaries aged 65 or older who died between the 1998 and 2012 survey waves and whose proxies responded to subsequent HRS exit surveys (72\% of all Medicare-linked decedents). The characteristics of our study population are summarized in Table 1. The respondents included 5548 (78.1\%) non-Hispanic whites, 1030 (14.5\%) non-Hispanic blacks, 331 (4.7\%) Hispanics, and 196 (2.8\%) persons of other race/ethnicity. Mean total Medicare expenditures across the study population in the last 6 months of life, adjusted to 2012 U.S. dollars were $\$ 41,712$ (range $\$ 0$ to $\$ 754,124$ ).

Table 2 reports rate ratio (RR) estimates provided by the sequential models to explain racial and ethnic differences in EOL expenditures. While controlling for previously hypothesized explanatory variables that contribute to differences in racial and ethnic spending at the EOL, the final model shows that despite controlling for all of these factors, there was still a significant difference in spending for non-Hispanic white, black, and Hispanic decedents.

The unadjusted results of model (1) show that Medicare expenditures for black decedents were 35\% more than for whites (RR 1.35, 95\% CI 1.26-1.44) and Medicare expenditures for Hispanics were $42 \%$ more than for whites (RR 1.42, 95\% CI 1.27-1.59). Model (2) accounted for demographic and social support by including model covariates for gender, age, marital status, residential status, and birth cohort. Only age and residential status had a statistically significant independent association with EOL Medicare expenditures. Living with others in the decedent's home was associated with increased spending at the EOL (RR 1.08, 95\%CI 1.01-1.16), while living in a nursing home was associated with decreased EOL Medicare spending (RR 0.83, 95\% CI 0.77-0.89). Controlling for demographic covariates reduced the difference in expenditures to $31 \%$ (RR 1.31, 95\% CI 1.22-1.40) for black decedents compared to whites, while expenditures for Hispanic decedents remained stable at $41 \%$ more than whites (RR 1.41, 95\% CI 1.26-1.58). 
Model (3) added socioeconomic and geographic indicators to the demographic and social support variables of model (2), which further reduced discrepancies in EOL Medicare expenditures. Included in this model were educational attainment, net worth (by quartile), urban residence, regional End of Life Expenditure Index (EOL-EI) by quintile, and additional insurance (Medicaid, VA insurance and private/Medigap were included). Of those, urban residence (RR 1.14, 95\% CI 1.07-1.20), Medicaid (RR 1.08, 95\% CI 1.01-1.16) and private/Medigap insurance (RR 1.07, 95\% CI 1.01-1.13) were statistically significantly associated with increased EOL expenditures for all races/ethnicities. Each EOL-EI quintile contributed an increasing proportion of expenditures. Adjusting for demographic, socioeconomic and geographic indicators in this model reduced the difference between both black/white EOL expenditures and Hispanic/white expenditures to $25 \%$ (RR 1.25, 95\% CI 1.16-1.34) and $27 \%$ (RR 1.27, 95\% CI 1.13-1.42), respectively.

Model (4) considered illness burden in addition to demographic, socioeconomic and geographic factors in evaluating expenditures. Factors included in this model were individual Elixhauser comorbidities, cognitive function,_and functional status based on number of ADL limitations. Of the 30 Elixhauser comorbidities included in the model, only 11 of those had a statistically significant association with EOL Medicare expenditures (Appendix Table 1). Dementia was associated with a statistically significant reduction in EOL Medicare spending (RR 0.87, 95\% CI 0.81-0.93). Model (4) further decreased the difference in EOL spending for blacks and Hispanics compared to non-Hispanic whites to 20\% (RR1.20, 95\% CI 1.12-1.29) and $21 \%$ (RR 1.21, 95\% CI 1.08-1.31) respectively.

Finally, model (5) includes EOL planning factors. These variables include presence of an advance directive, discussion of EOL treatment preferences, and if death was expected. Having an expected death was associated with increased Medicare expenditures in the last six months of life. Neither the presence of an advance directive, nor discussion of treatment preferences for the final days of life were significantly associated with average EOL Medicare expenditures. An expected death was associated with an increase in EOL expenditures by $24 \%$ (RR1.24, 95\% CI 1.18-1.30) compared with those whose death was unexpected. Controlling for demographic, socioeconomic, geographic, medical, and end-of-life specific factors in this model shows expenditures for black decedents were 22\% (RR1.22, 95\% CI 1.13-1.31) higher and expenditures 
for Hispanic decedents were 19\% (RR 1.19, 95\% CI 1.06-1.33) higher than for non-Hispanic whites.

Figure 2 illustrates the mean differences in EOL expenditures by race for the unadjusted model (1) compared to the fully adjusted model (5). In unadjusted analyses, Medicare expenditures for black decedents was on average \$13,522 more than for non-Hispanic whites, and Medicare expenditures for Hispanic decedents was \$16,341 more. Accounting for all measured demographic, socioeconomic, geographic, medical, and EOL specific factors, Medicare expenditures for black decedents was on average \$7,185 more than for non-Hispanic whites, while expenditures for Hispanic decedents was \$6,164 more.

\section{DISCUSSION}

In this national sample of decedents, significantly higher Medicare expenditures in nonHispanic black and Hispanic decedents were not fully explained by an extensive array of patient characteristics. Tested variables included demographic and social supports, socioeconomic status, geography, medical, and EOL planning factors. As prior studies examining a more limited range of factors found, these variables did explain some of the variation in EOL spending between racial and ethnic groups $(5,8,9,12,13,33,34)$. However, even in our fully adjusted models, approximately half of the variation remains unaccounted for.

Differences between racial and ethnic groups in Medicare spending in the last six months of life are frequently attributed to differences in patient preferences $(2,3,5,14,33,35)$. Qualitative survey work supports the conclusion that non-white patients are more likely to prefer life-sustaining treatments and more likely to prefer to die in the hospital compared to white patients $(2,3,16,35-40)$. However, inferring that unexplained variation in expenditures is due largely to these differences in preferences risks minimizing the extent to which other systemic or organizational factors contribute to this expenditure difference. Indeed, questions have been raised as to whether patient preferences_-by any patient of any race- have any substantial effect on EOL care $(7,10,13,36,41)$. Therefore, our analysis systematically examined several mechanisms that might contribute to racial and ethnic differences in EOL Medicare expenditures, including some aspects of preferences. Our analysis suggests that EOL expenditure variation remains after controlling for many patient-oriented factors. 
In this way, EOL expenditures are unlike many other health outcomes that have been evaluated for the effects of race and ethnicity. Prior studies have demonstrated that often what appears to be a race effect on health outcomes can actually be explained by other mechanisms, such as socioeconomic status, health literacy, clinical factors, hospital or neighborhood level effects, or insurance status $(3,4,9,11,42-45)$. While our study included these factors, all of which somewhat attenuated the measured association with EOL Medicare expenditures between racial and ethnic groups, they failed to explain the total difference. This highlights how complexities surrounding care and decision-making at the EOL can be difficult to capture.

Our results suggest that factors which were not measured in our analysis—or in prior analyses-may be important to consider. Following our modeling framework, we were able to systematically eliminate several explanatory mechanisms for racial and ethnic variation in EOL Medicare expenditures. We suspect it is unlikely that the residual expenditure differentials are due solely to remaining patient-level factors, specifically preferences for life-prolonging treatment. Rather, we hypothesize that larger system-level or network-based factors are contributing to this unexplained difference. Important unexplored mechanisms potentially include interactions with the health care system, such as patient-family communication, patientprovider factors, and provider-provider interactions. As the literature in this area frequently focuses on patient level characteristics, insufficient attention has been paid to caregiver, provider, or health system contributions to EOL expenditures. Disagreements between family or other surrogates and patient preferences are well documented (35), yet little data exists as to how family or surrogate characteristics may be associated with EOL expenditures. Additionally, providers make assumptions based on presumed EOL preference differences by race, and thereby contribute to overall Medicare expenditures by providing unwanted life-sustaining care $(8,41,46,47)$. Further research is needed to understand if including family or caregiver and provider-level factors explains more of the variation in EOL expenditures between racial and ethnic groups. Much of the work in this domain has included evaluating additional patient level variables to understand EOL expenditure differences between racial and ethnic groups. There are many stakeholders involved at the EOL, and opportunities exist for these parties to exert influence in decisions for high cost care.

Our study has a number of potential limitations. Medicare expenditures do not account for all health care costs incurred by the decedent. Nursing home costs and expenditures covered 
by other insurance providers are not captured using these data and likely contribute significantly to total overall spending at the EOL. Out-of-Pocket costs for patients and families were also not included in this analysis and can be substantial at the EOL (48). Despite adjusting for hospital referral regions, facilities may vary within HRRs. We were not able to adjust for physician- or facility-level factors that may influence EOL care and utilization (49). The HRS for this time period lacks the sample size to study other racial and ethnic groups, therefore our analysis was limited to white, black and Hispanic decedents. By identifying decedents and looking retrospectively, our data are subject to selection bias because we cannot account for those who survived in the same cohort despite a high risk of death. Finally, data from proxy respondents in exit interviews were collected retrospectively and could be subject to recall bias.

Our study finds that both known and previously unexamined mechanisms do not fully explain racial and ethnic differences in EOL Medicare expenditures. Having individual respondent and proxy data over 14 years of survey collection provided a more detailed understanding of specific EOL planning factors that were unable to be examined on a national level in previous studies (5). However, much of the variation in expenditures remains unexplained. We suggest that future research should focus on broader systemic, organizational, or social-network factors that might underlie racial and ethnic differences in EOL spending. Such information is essential to developing policies and programs to understand and improve these factors that contribute to differences in care and spending at the end of life.

\section{ACKNOWLEDGMENTS:}

Prior Presentations: This work has been presented as a plenary presentation at the Robert Wood Johnson Foundation Clinical Scholars National Meeting U November 2015, Seattle, WA. Funding Source: EB and JH were supported by the Robert Wood Johnson Foundation Clinical Scholars Program.

Conflict of Interest: The editor in chief has reviewed the conflict of interest checklist provided by the authors and has determined that the authors have no financial or any other kind of personal conflicts with this paper.

Author Contributions: EB contributed to study conceptualization and design, research, extraction and analysis of data, drafting of manuscript. TI contributed to conceptualization and design, analysis of data, drafting of manuscript. JH contributed to conceptualization and design, 
analysis of data and drafting of manuscript. KL contributed to study conceptualization and design, extraction of data and drafting of manuscript.

Sponsor's Role: None

\section{REFERENCES}

1. Akinyemiju TF, Soliman AS, Johnson NJ et al. Individual and neighborhood socioeconomic status and healthcare resources in relation to black-white breast cancer survival disparities. J Cancer Epidemiol 2013;2013.

2. Barnato AE, Anthony DL, Skinner J et al. Racial and Ethnic Differences in Preferences for Endof-Life Treatment. J gen intern med 2009;24:695-701.

3. Borum ML, Lynn J, Zhong Z. The effects of patient race on outcomes in seriously ill patients in SUPPORT: An overview of economic impact, medical intervention, and end-of-life decisions. Study to understand prognoses and preferences for outcomes and risks of treatments. J Am Geriatri Soc 2000;48(5 Suppl):S194-S198.

4. Chan PS, Nichol G, Krumholz HM et al. Racial differences in survival after in-hospital cardiac arrest. JAMA 2009;302:1195-1201.

5. Hanchate A, Kronman AC, Young-Xu Y et al. Racial and ethnic differences in end-of-life costs: Why do minorities cost more than whites? Arch Intern Med 2009;169:493-501.

Hopp FP, Sonia AD. Racial variations in end-of-life care. J Am Geriatr Soc 2000;48:658-663.

Kelley AS, Ettner SL, Morrison RS et al. Determinants of medical expenditures in the last 6 months of life. Ann Intern Med 2011;154:235-42.

8. Loggers ET, Maciejewski PK, Paulk E et al. Racial differences in predictors of intensive end-oflife care in patients with advanced cancer. J Clin 2009; 27:5559-5564.

9. Merchant RM, Becker LB, Yang F et al. Hospital racial composition: A neglected factor in cardiac arrest survival disparities. Am Heart J 2011;161:705-711.

10. Muni S, Engelberg Ra, Treece PD et al. The influence of race/ethnicity and socioeconomic status on end-of-life care in the ICU. Chest 2011;139:1025-1033.

11. Roseland ME, Pressler ME, Lamerato LE et al. Racial differences in breast cancer survival in a large urban integrated health system. Cancer 2015;121:3668-3675.

12. Smith AK, Earle CC, McCarthy EP. Racial and ethnic differences in end-of-life care in fee-forservice medicare beneficiaries with advanced cancer. J Am Geriatr Soc 2009;57:153-158. 
13. Welch LC, Teno JM, Mor V. End-of-life care in black and white: Race matters for medical care of dying patients and their families. J Am Geriatr Soc 2005;53:1145-1153.

14. Johnson KS. Racial and ethnic disparities in palliative care. J Palliat Med 2013;16:1329-1334.

15. Kelley AS, Morrison RS, Wenger NS et al. Determinants of treatment intensity for patients with serious illness: A new conceptual framework. J Palliat Med 2010;13:807-813.

16. Barnato AE, Herndon MB, Anthony DL et al. Are regional variations in end-of-life care intensity explained by patient preferences?: A Study of the US Medicare Population. Medical Care 2007;45:386393.

17. Hogan C, Lunney J, Gabel J et al. Medicare beneficiaries' costs of care in the last year of life. Health Aff 2001;20:188-195.

18. Karikari-Martin P, McCann JJ, Farran CJ et al. Race, any cancer, income, or cognitive function: What inf luences hospice or aggressive services use at the end of life among community-dwelling Medicare beneficiaries? Am J Hosp Palliat Care 2015.

19. Shugarman LR, Campbell DE, Bird CE et al. Differences in Medicare expenditures during the last 3 years of life. J Gen Intern Med 2004;19:127-135.

20. Heisler M, Faul JD, Hayward RA et al. Mechanisms for racial and ethnic disparities in glycemic control in middle-aged and older Americans in the health and retirement study. Arch Intern Med 2007;167:1853-1860.

21. Juster FT, Suzman R. An Overview of the Health and Retirement Study. J Hum Resources 1995;30:S7-S56.

22. Medicare Advantage: The Henry J. Kaiser Family Foundation; 2015 [updated June 19, 2015; cited 2016 December 13]. Available from: http://kff.org/medicare/fact-sheet/medicare-advantage/. 23. Landon BE, Zaslavsky AM, Saunders RC et al. Analysis Of Medicare Advantage HMOs compared with traditional Medicare shows lower use of many services during 2003-09. Health Aff 2012;31:2609-2617.

24. Stevenson DG, Ayanian JZ, Zaslavsky AM et al. Service use at the end-of-life in Medicare advantage versus traditional Medicare. Med Care 2013;51:931-937.

25. Zuckerman S, Waidmann T, Berenson R et al. Clarifying sources of geographic differences in Medicare spending. New Engl J Med 2010;363:54-62.

26. Fisher ES, Wennberg DE, Stukel TA et al. The implications of regional variations in Medicare spending. Part 2: Health outcomes and satisfaction with care. Ann Intern Med 2003;138:288-298.

27. Fisher ES, Wennberg DE, Stukel TA et al. The implications of regional variations in Medicare spending. Part 1: The content, quality, and accessibility of care. Ann Intern Med 2003;138:273-287. 
28. Elixhauser A, Steiner C, Harris DR et al. Comorbidity measures for use with administrative data. Medical Care 1998;36:8-27.

29. Ofstedal MB FG, Herzog AR. Documentation of Cognitive Functioning Measures in the Health and Retirement Study. Ann Arbor, MI: University of Michigan, 2005.

30. Crimmins EM, Kim JK, Langa KM et al. Assessment of cognition using surveys and neuropsychological assessment: The Health and Retirement Study and the Aging, Demographics, and Memory Study. J Gerontol B Psychol Sci Soc Sci 2011;66 (Suppl 1):i162-71.

31. Manning WG, Basu A, Mullahy J. Generalized modeling approaches to risk adjustment of skewed outcomes data. J Health Econ 2005;24:465-488.

32. Schafer JL. Multiple imputation: A primer. Stat Methods Med Res 1999;8:3-15.

33. Shugarman LR, Decker SL, Bercovitz A. Demographic and social characteristics and spending at the end of life. J Pain Sympt Manage 2009;38:15-26.

34. Shugarman LR, Sorbero ME, Tian $\mathrm{H}$ et al. An exploration of urban and rural differences in lung cancer survival among medicare beneficiaries. Am J Public Health 2008;98:1280-1287.

35. Phipps E, True G, Harris D et al. Approaching the end of life: attitudes, preferences, and behaviors of African-American and white patients and their family caregivers. J Clin Oncol 2003;21:549554.

36. A controlled trial to improve care for seriously ill hospitalized patients. The study to understand prognoses and preferences for outcomes and risks of treatments (SUPPORT). The SUPPORT Principal Investigators. JAMA 1995;274:1591-1598.

37. Garrido MM, Harrington ST, Prigerson HG. End-of-life treatment preferences: A key to reducing ethnic/racial disparities in advance care planning? Cancer 2014: 120: 3981-3986.

38. Blackhall LJ, Frank G, Murphy ST et al. Ethnicity and attitudes towards life sustaining technology. Soc Sci Med 1999;48:1779-89.

39. Kagawa-Singer M, Blackhall LJ. Negotiating cross-cultural issues at the end of life: "You got to go where he lives". JAMA 2001;286:2993-3001.

40. Kwak J, Haley WE. Current research findings on end-of-life decision making among racially or ethnically diverse groups. Gerontologist 2005;45:634-641.

41. Mack JW, Paulk ME, Viswanath $\mathrm{K}$ et al. Racial disparities in the outcomes of communication on medical care received near death. Arch Intern Med 2010;170:1533-1540.

42. Cooke CR, Nallamothu B, Kahn JM et al. Race and timeliness of transfer for revascularization in patients with acute myocardial infarction. Med Care 2011;49:662-667.

43. LaVeist Ta, Thorpe RJ, Galarraga JE et al. Environmental and socio-economic factors as contributors to racial disparities in diabetes prevalence. J Gen Intern Med 2009;24:1144-1148. 
44. Volandes AE, Paasche-Orlow M, Gillick MR et al. Health literacy not race predicts end-of-life care preferences. J Palliat Med 2008;11:754-762.

45. Johnson KS, Kuchibhatla M, Payne R et al. Race and residence: Intercounty variation in blackwhite differences in hospice use. J Pain Symptom Manage 2013;46:681-690.

46. LoPresti Ma, Dement F, Gold HT. End-of-life care for people with cancer from ethnic minority groups: A systematic review. Am J Hosp Palliat Med 2016;33:291-305.

47. Wallace MP, Weiner JS, Pekmezaris R et al. Physician cultural sensitivity in African American advance care planning: a pilot study. J Palliat Med 2007;10:721-727.

48. Kelley AS, McGarry K, Gorges R et al. The burden of health care costs for patients with dementia in the last 5 years of life. Ann Intern Med 2015;163:729-736.

49. Obermeyer Z, Powers BW, Makar M et al. Physician characteristics strongly predict patient enrollment in hospice. Health Aff (Millwood) 2015;34:993-1000.

\section{Table 1: Decedent Characteristics by Race/Ethnicity}

\begin{tabular}{|c|c|c|c|c|}
\hline Characteristic & $\begin{array}{c}\text { Non-Hispanic } \\
\text { white }\end{array}$ & Black & Hispanic & $\begin{array}{c}\text { Other } \\
\text { Minority }\end{array}$ \\
\hline $\mathrm{N}(7,105)$ & 5548 & 1030 & 331 & 196 \\
\hline Age, mean $( \pm \mathrm{SD})$ & $83.0( \pm 8.47)$ & $81.2( \pm 9.27)$ & $82.5( \pm 9.11)$ & $79.5( \pm 8.71)$ \\
\hline Women, $\mathrm{n}$ & $3016(54.4)$ & $592(57.5)$ & $174(52.6)$ & $94(48.0)$ \\
\hline \multicolumn{5}{|l|}{ Marital Status, n (\%) } \\
\hline Married & $2477(44.7)$ & $336(32.7)$ & $143(43.3)$ & $80(41.0)$ \\
\hline Never Married & $157(2.83)$ & $45(4.37)$ & $13(3.94)$ & $10(5.13)$ \\
\hline Widow & 2529 (45.6) & $515(50.1)$ & $137(41.5)$ & $84(4301)$ \\
\hline Separated/Divorced & $384(6.92)$ & $133(12.9)$ & $37(11.2)$ & $21(10.8)$ \\
\hline \multicolumn{5}{|l|}{ Living situation, $\mathrm{n}(\%)$} \\
\hline Lives alone & $1497(27.0)$ & $273(26.5)$ & $82(24.8)$ & $50(25.5)$ \\
\hline Lives with others & $2989(53.9)$ & $560(54.4)$ & $204(61.6)$ & $112(57.1)$ \\
\hline Lives in nursing home & $1062(19.1)$ & $197(19.1)$ & $45(13.6)$ & $34(17.4)$ \\
\hline \multicolumn{5}{|l|}{ Educational attainment, n (\%) } \\
\hline$<12 \mathrm{y}$ & $1963(35.4)$ & $676(65.6)$ & $260(78.6)$ & $138(70.4)$ \\
\hline $12 y$ & $1901(34.3)$ & $204(19.8)$ & $34(10.3)$ & $26(13.3)$ \\
\hline $13-15 y$ & $932(16.8)$ & $81(7.86)$ & $23(6.95)$ & $15(7.65)$ \\
\hline$>16 y$ & $750(13.5)$ & $69(6.70)$ & $14(4.23)$ & $17(8.67)$ \\
\hline \multicolumn{5}{|l|}{ Birth year cohort, n (\%) } \\
\hline $\operatorname{AHEAD}(<1923)$ & $3259(58.7)$ & $544(52.8)$ & $189(57.1)$ & $80(40.8)$ \\
\hline
\end{tabular}




\begin{tabular}{|c|c|c|c|c|}
\hline CODA (1923-30) & $1181(21.3)$ & $161(15.6)$ & $59(17.8)$ & $53(27.0)$ \\
\hline HRS (1931-41) & $1061(19.1)$ & $307(29.8)$ & $79(23.9)$ & $57(29.1)$ \\
\hline War Baby (1942-47) & $47(0.85)$ & $18(1.75)$ & $4(1.21)$ & $6(3.06)$ \\
\hline Net wealth median in 2012 USD & 141,796 & 17,469 & 16,610 & 10,141 \\
\hline$( \pm \mathrm{SD})$ & $( \pm 1,205,068)$ & $( \pm 189637)$ & $( \pm 244,258)$ & $( \pm 544,775)$ \\
\hline Urban residence, $\mathrm{n}(\%)$ & $2116(38.2)$ & $508(49.4)$ & $137(41.5)$ & $75(38.5)$ \\
\hline \multicolumn{5}{|l|}{ Additional Insurance coverage, $\mathrm{n}(\%)$} \\
\hline Medicaid & $823(15.1)$ & $388(39.4)$ & $181(55.9)$ & $85(44.3)$ \\
\hline Veterans Administration & $263(4.78)$ & $34(3.38)$ & $7(2.12)$ & $8(4.17)$ \\
\hline MediGap (private) & $3524(66.0)$ & $300(30.4)$ & $59(18.2)$ & $50(26.2)$ \\
\hline \multicolumn{5}{|l|}{ EOL_EI ${ }^{\mathrm{a}}$ quintile } \\
\hline 1 & $800(14.5)$ & $140(13.7)$ & $14(4.29)$ & $18(9.18)$ \\
\hline 2 & $1006(18.2)$ & $200(19.6)$ & $6(1.84)$ & $19(9.69)$ \\
\hline 3 & $1327(24.0)$ & $114(11.2)$ & $39(12.0)$ & $27(13.8)$ \\
\hline 4 & $974(17.6)$ & $203(19.9)$ & $54(16.6)$ & $52(26.5)$ \\
\hline 5 & $1420(25.7)$ & $362(35.5)$ & $213(65.3)$ & $80(40.8)$ \\
\hline \multicolumn{5}{|c|}{ Functional status (\# of $\mathrm{ADL}^{\mathrm{b}}$ deficiencies) } \\
\hline independent $(0)$ & $2152(38.9)$ & $338(33.0)$ & $104(31.6)$ & $73(37.8)$ \\
\hline mod impairment (1-3) & $1890(34.2)$ & $335(32.7)$ & $111(33.7)$ & $61(31.6)$ \\
\hline severe impairment $(>4)$ & $1489(26.9)$ & $351(34.3)$ & $114(34.7)$ & $59(30.6)$ \\
\hline \multicolumn{5}{|l|}{ Chronic medical conditions } \\
\hline $\mathrm{CHF}^{\mathrm{C}}$ & $1666(30.0)$ & $310(30.1)$ & 105 (31.7) & $63(32.1)$ \\
\hline Chronic pulmonary disease & $1565(28.2)$ & $243(23.6)$ & $106(32.0)$ & $66(33.7)$ \\
\hline $\begin{array}{l}\text { Hypertension (complicated }+ \\
\text { uncomplicated) }\end{array}$ & $3594(50.6)$ & $898(12.6)$ & $273(3.84)$ & $136(1.91)$ \\
\hline $\begin{array}{l}\text { Diabetes (complicated + } \\
\text { uncomplicated) }\end{array}$ & $1761(24.8)$ & $517(7.28)$ & $206(2.90)$ & $99(1.39)$ \\
\hline Renal Failure & $662(11.9)$ & $208(20.2)$ & $62(18.7)$ & $33(16.8)$ \\
\hline Liver disease & $150(2.7)$ & $30(2.91)$ & $15(4.53)$ & $11(5.61)$ \\
\hline Lymphoma & $114(2.05)$ & $14(1.36)$ & $3(0.91)$ & $2(1.02)$ \\
\hline Metastatic Cancer & $317(5.71)$ & $58(5.63)$ & $14(4.23)$ & $8(4.08)$ \\
\hline Solid tumor & $951(17.1)$ & $172(16.7)$ & $45(13.6)$ & $20(10.2)$ \\
\hline Depression & $729(13.1)$ & $82(7.96)$ & $49(14.8)$ & $23(11.7)$ \\
\hline$\geq 2$ comorbidities $\left(\mathrm{CCI}^{\mathrm{c}}\right)$ & $3195(57.6)$ & $648(62.9)$ & $213(64.4)$ & $124(63.3)$ \\
\hline \multicolumn{5}{|l|}{ Cognitive Function } \\
\hline Normal & $2270(41.7)$ & 209 (20.9) & $80(24.6)$ & $39(20.3)$ \\
\hline Mild cognitive impairment & $1465(26.9)$ & $295(29.5)$ & $86(26.5)$ & $65(33.9)$ \\
\hline
\end{tabular}




\begin{tabular}{|c|c|c|c|c|}
\hline Severe cognitive & $1706(31.4)$ & 496 (49.6) & 159 (48.9) & $88(45.8)$ \\
\hline \multicolumn{5}{|l|}{ impairment/dementia } \\
\hline Median days in hospital $\left(\mathrm{IQR}^{\mathrm{e}}\right)$ & $7(0-16)$ & $11(0-25)$ & $12(0-25)$ & $10(0-20)$ \\
\hline Advanced Directive, n (\%) & $3468(71.9)$ & $332(37.6)$ & $89(31.2)$ & $74(42.1)$ \\
\hline \multicolumn{5}{|l|}{ Discussed Treatment Preferences } \\
\hline yes & $2937(58.7)$ & $373(38.4)$ & $114(37.5)$ & $95(48.7)$ \\
\hline no & $2016(40.3)$ & $588(60.6)$ & $186(61.2)$ & $95(48.7)$ \\
\hline unsure & $47(0.94)$ & $10(1.03)$ & $4(1.32)$ & $5(2.56)$ \\
\hline Died in Hospital, $\mathrm{n}(\%)$ & $1605(29.3)$ & $387(38.7)$ & $129(39.9)$ & $72(36.9)$ \\
\hline sst 6 months, $\mathrm{n}(\%)$ & $2070(37.3)$ & $258(25.1)$ & $95(28.7)$ & $57(20.1)$ \\
\hline \multicolumn{5}{|l|}{ Death expected? } \\
\hline yes & $3150(62.3)$ & $492(52.5)$ & $181(60.1)$ & $99(53.5)$ \\
\hline no & $1897(37.5)$ & $441(47.0)$ & $117(38.9)$ & $84(45.4)$ \\
\hline unsure & $13(0.26)$ & $5(0.53)$ & $3(1.00)$ & $2(1.08)$ \\
\hline Median time to death ${ }^{\mathrm{f}}$, mos & 14.9 & 14.4 & 13.9 & 15.2 \\
\hline (IQR) & $(7.61-22.2)$ & $(7.36-21.8)$ & $(6.77-22.3)$ & $(8.32-21.6)$ \\
\hline
\end{tabular}

\footnotetext{
${ }^{a}$ EOL-EI: End of Life Expenditure Index

${ }^{\mathrm{b}}$ Activities of Daily Living

${ }^{\mathrm{c}}$ Congestive Heart Failure

${ }^{\mathrm{d}}$ Charlson Comorbidity Index

${ }^{\mathrm{e}}$ Interquartile Range

${ }^{\mathrm{f}}$ Number of months between last core interview and death
}

\section{Table 2: Models Examining Explanatory Factors Contributing to Racial/Ethnic Differences in Medicare Spending in the Last 6 Months of Life}

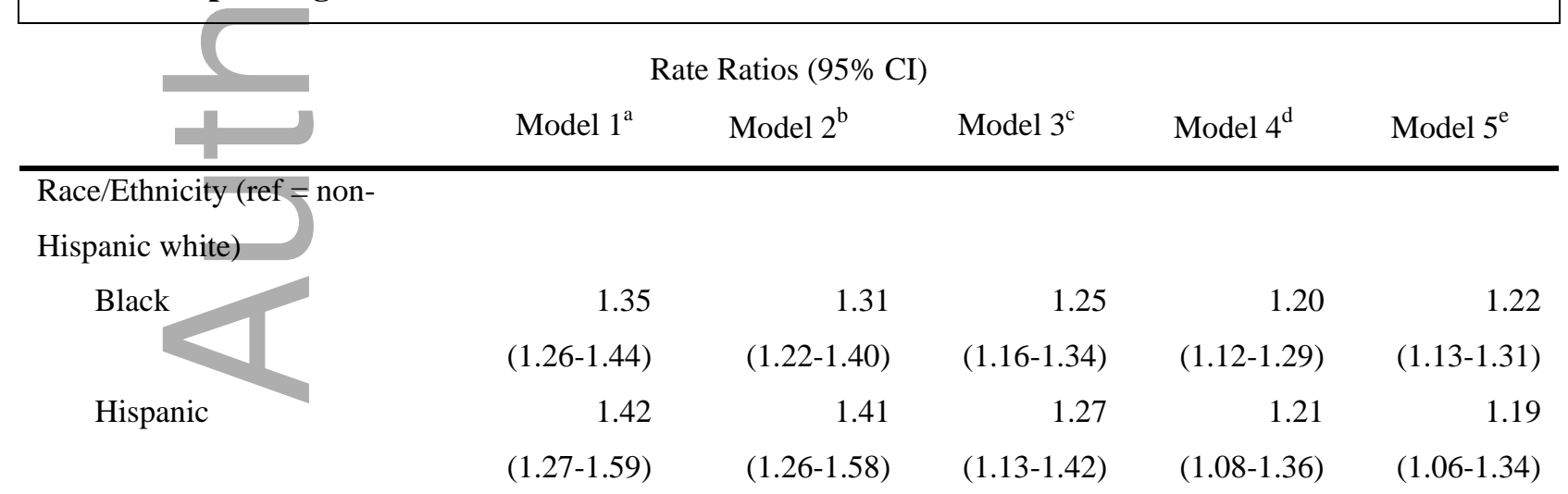

Demographic \& Social Supports 


\begin{tabular}{|c|c|c|c|c|}
\hline female & 1.03 & 1.02 & 1.02 & 1.00 \\
\hline & $(0.98-1.08)$ & $(0.97-1.07)$ & $(0.96-1.07)$ & $(0.95-1.06)$ \\
\hline age & 1.06 & 1.06 & 1.02 & 1.02 \\
\hline & $(1.00-1.12)$ & $(1.01-1.12)$ & $(0.97-1.07)$ & $(0.97-1.08)$ \\
\hline Marital Status $(r e f=$ married & & & & \\
\hline never ma & 0.99 & 0.96 & 0.99 & 0.99 \\
\hline & $(0.86-1.14)$ & $(0.83-1.10)$ & $(0.86-1.14)$ & $(0.86-1.14)$ \\
\hline widowed & 1.03 & 1.02 & 1.05 & 1.05 \\
\hline & $(0.96-1.10)$ & $(0.95-1.09)$ & $(0.98-1.12)$ & $(0.86-1.13)$ \\
\hline divorced/s & 1.02 & 0.98 & 0.98 & 0.98 \\
\hline & $(0.92-1.13)$ & $(0.89-1.09)$ & $(0.89-1.08)$ & $(0.89-1.08)$ \\
\hline Residential s & & & & \\
\hline home alone) & & & & \\
\hline Lives home with others & 1.08 & 1.07 & 1.09 & 1.09 \\
\hline & $(1.01-1.16)$ & $(1.00-1.14)$ & $(1.02-1.17)$ & $(1.02-1.17)$ \\
\hline ng home & 0.83 & 0.82 & 0.89 & 0.87 \\
\hline & $(0.77-0.89)$ & $(0.76-0.88)$ & $(0.82-0.97)$ & $(0.81-0.95)$ \\
\hline cohort (refere & & & & \\
\hline CODA $(1923-1930)$ & 0.96 & 0.98 & 0.94 & 0.93 \\
\hline & $(0.89-1.03)$ & $(0.92-1.06)$ & $(0.87-1.01)$ & $(0.87-1.00)$ \\
\hline HRS (1931-1941) & 1.07 & 1.13 & 0.99 & 0.99 \\
\hline & $(0.97-1.19)$ & $(1.02-1.25)$ & $(0.89-1.09)$ & $(0.88-1.10)$ \\
\hline War Baby (1942-1947) & 0.95 & 1.06 & 0.88 & 0.88 \\
\hline & $(0.73-1.23)$ & $(0.83-1.37)$ & $(0.68-1.13)$ & $(0.68-1.13)$ \\
\hline
\end{tabular}

Socioeconomic \& Geographic Indicators

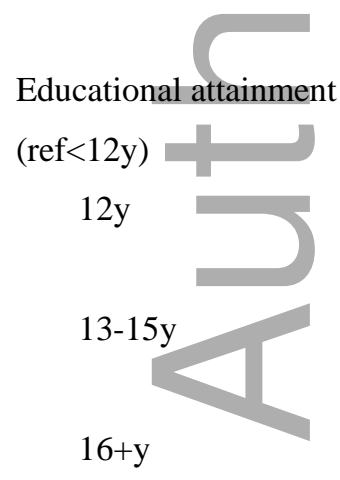

$\begin{array}{rrr}1.01 & 0.99 & 0.98 \\ (0.96-1.07) & (0.93-1.04) & (0.92-1.04) \\ 0.96 & 0.94 & 0.94 \\ (0.90-1.03) & (0.87-1.01) & (0.87-1.01) \\ 1.04 & 1.00 & 0.99 \\ (0.96-1.12) & (0.93-1.09) & (0.91-1.07)\end{array}$

Net worth (ref $=1$ st quartile $)$ 
2

3

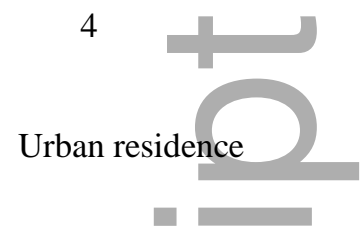

EOL ${ }^{\mathrm{f}}$ Expenditure Index (ref $=$ $1^{\text {st }}$ quintile)

2

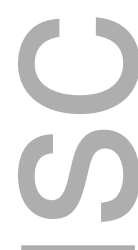

4

5

Additional Insurance

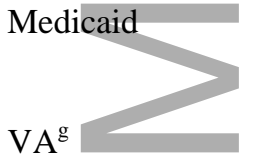

Medigap (private)

\section{Illness Burden}

Functional Status (ref $=0$ ADL

limitations)

moderate impairment

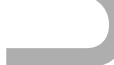

severe impairment

(30 indices)

Cognitive Function $($ ref $=$

\footnotetext{
Elixhauser Comorbidities
}

$\begin{array}{rrr}0.98 & 0.98 & 0.99 \\ (0.91-1.05) & (0.92-1.06) & (0.92-1.06) \\ 0.99 & 1.02 & 1.02 \\ (0.92-1.07) & (0.95-1.10) & (0.95-1.10) \\ 1.01 & 1.07 & 1.07 \\ (0.93-1.10) & (0.98-1.16) & (0.98-1.17) \\ 1.14 & 1.12 & 1.12 \\ (1.07-1.20) & (1.06-1.18) & (1.06-1.19)\end{array}$

$\begin{array}{rrr}1.19 & 1.19\end{array}$

(1.09-1.29)

(1.10-1.30)

(1.09-1.29)

1.21

1.19

1.19

(1.12-1.31)

(1.10-1.29)

(1.09-1.28)

1.25

1.22

1.23

(1.15-1.36)

(1.12-1.32)

(1.13-1.34)

1.50

1.43

1.43

(1.38-1.63)

(1.32-1.56)

(1.32-1.56)

1.08

1.03

1.04

(1.01-1.16)

(0.96-1.11)

(0.97-1.12)

0.90

0.84

0.84

(0.81-1.01)

(0.75-0.95)

(0.75-0.94)

1.07

1.02

1.02

(1.01-1.13)

(0.97-1.08)

(0.97-1.08)

1.02

1.01

(0.97-1.08)

(0.96-1.07)

0.95

0.94

(0.89-1.02)

(0.87-1.01)

See appendix table 
normal)

Mild Cognitive Impairment

Dementia

\section{EOL Planning}

Discussed Preferences $(\mathrm{ref}=\mathrm{no})$

yes

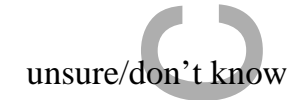

Had advance directive (ref=no)

yes

unsure/don't know

Expected death $($ ref $=$ no $)$

yes

\footnotetext{
${ }^{\mathrm{a}}$ Model 1: Unadjusted analysis

${ }^{\mathrm{b}}$ Model 2: Model $1+$ demographic and social support variables (gender, age, marital status, residential status, birth cohort)

${ }^{\mathrm{c}}$ Model 3: Model 2 + socioeconomic and geographic variables (educational attainment, net worth by quartile, urban residence, EOL-EI by quintile, additional insurance-Medicaid, VA, private/Medigap) ${ }^{\mathrm{d}}$ Model 4: Model 3 + illness burden (Elixhauser comorbidities, functional status by deficiencies in Activities of Daily Living, cognitive function)

${ }^{\mathrm{e}}$ Model 5: Model 4 + End-of-life specific factors (discussed EOL treatment preferences, presence of advance directive, death was expected)

${ }^{\mathrm{f}}$ End of Life

g Veterans Administration

${ }^{\mathrm{f}}$ Activities of Daily Living
}

Figure 1: Modeling Framework for Factors Contributing to Differences in End-of-Life Care. 


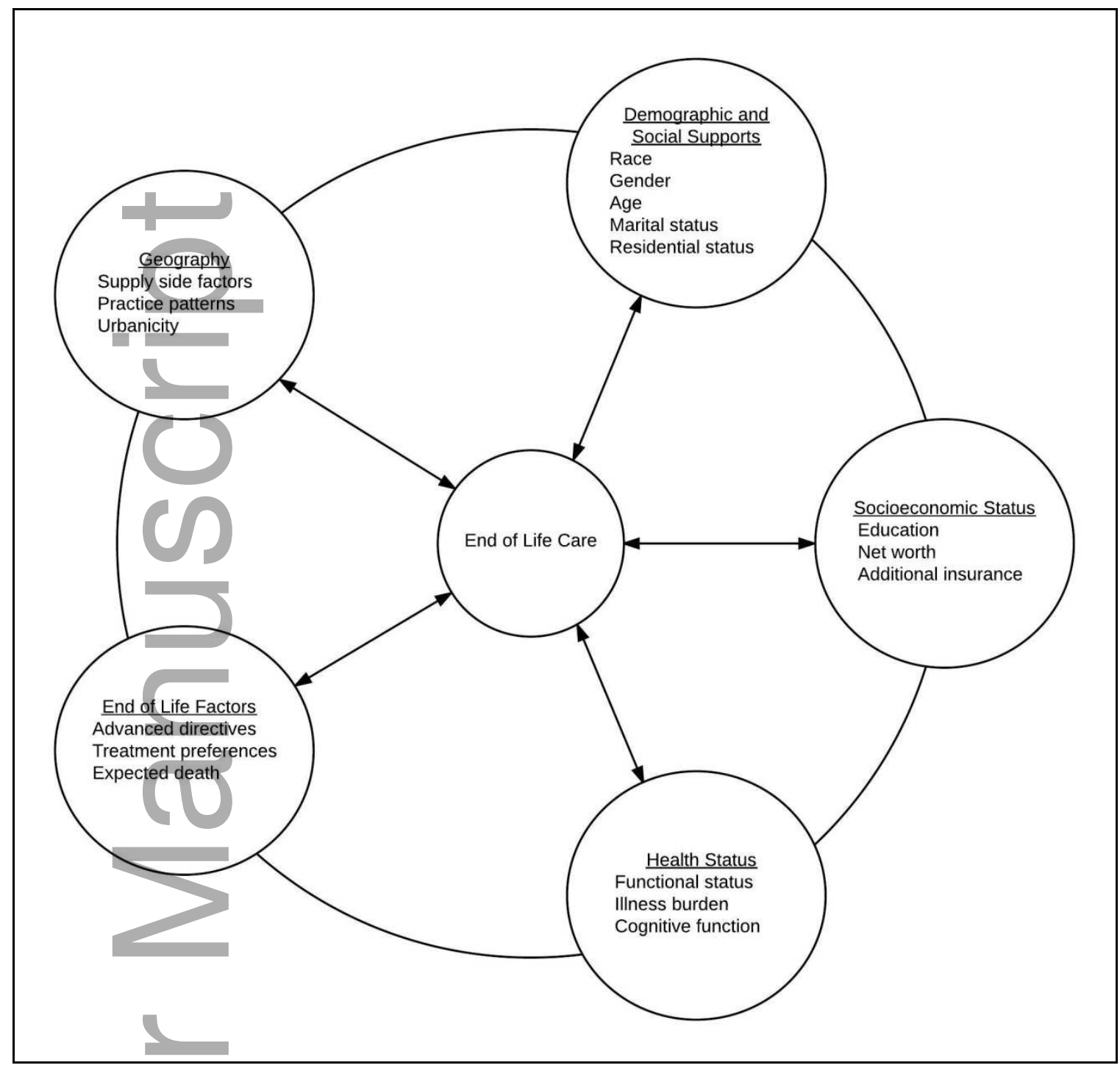

Figure 2: Predicted Mean Medicare Expenditures in the Last 6 Months of Life by Race/Ethnicity

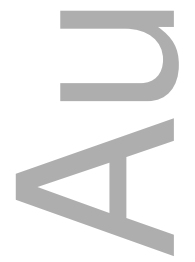




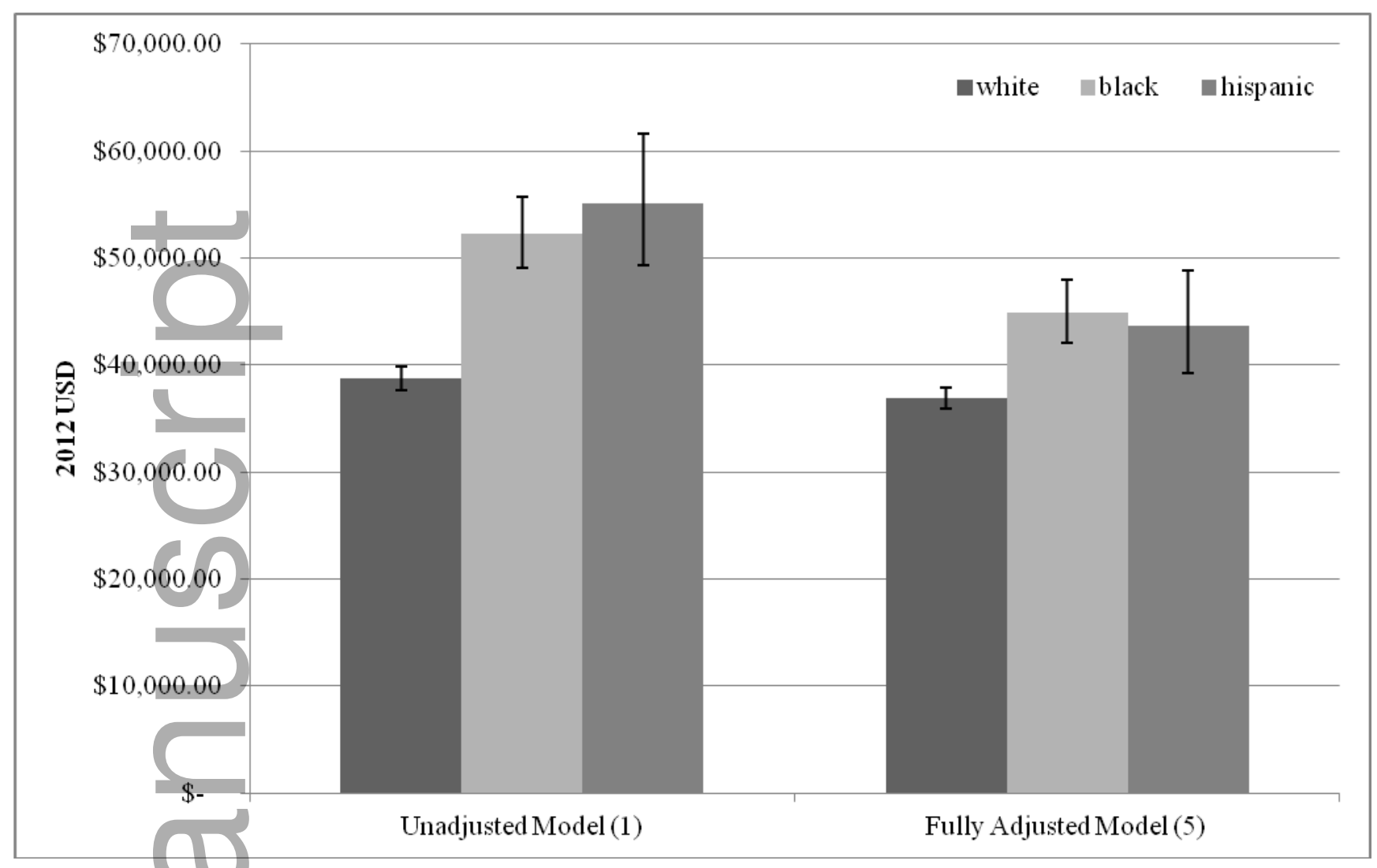

\section{FIGURE LEGENDS:}

Figure 1: Modeling Framework for Factors Contributing to Differences in End-of-Life Care.

Figure 2: Predicted Mean Medicare Expenditures in the Last 6 Months of Life by Race/Ethnicity Model (1): Unadjusted analysis of race and total Medicare expenditures.

Model (5): Multivariable analysis including all demographic \& social supports, socioeconomic factors, geographic factors, illness burden and end-of-life planning variables.

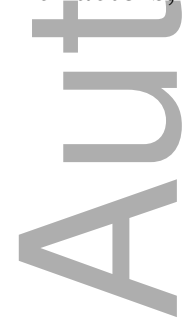

